\title{
Thromboembolism in inflammatory bowel disease: role of platelets
}

\author{
M J Webberley, M T Hart, V Melikian
}

\begin{abstract}
Patients with inflammatory bowel disease are susceptible to thromboembolism and recently small vessel thrombosis has been implicated as an aetiological factor in Crohn's disease. This study therefore investigated platelet function in 104 patients with inflammatory bowel disease of whom eight had previous thromboembolism. Thirty five patients had reproducible spontaneous platelet aggregation of more than $30 \%$ ( 0 in controls) $(\mathbf{p}<0.0001)$. A further 20 patients showed hypersensitivity of platelets to low concentrations of aggregating agents $(p<0.001)$. Plasma thromboxane $B_{2}$ and $\beta$ thromboglobulin levels were significantly higher than controls $(p<0.001$ and $p<0.001)$, but platelet lifespan studies were normal. There was no correlation with disease activity. Patients with inflammatory bowel disease have abnormal platelet activity; which may contribute to the inflammatory process. (Gut 1993; 34: 247-251)
\end{abstract}

An increased risk of major thromboembolism has been described in patients with inflammatory bowel disease ${ }^{1-6}$ with incidences as high as $39 \%$ in some postmortem studies. ${ }^{4}$ Young patients with active ulcerative colitis appear to be particularly susceptible with significant mortality. ${ }^{1-2}$ A climate of blood hypercoaguability has been described in patients with inflammatory bowel disease (IBD) and more recently, thrombosis, vasculitis, and tissue infarction have been proposed as contributing factors in Crohn's disease.? Examination of the clotting cascade has revealed significant abnormalities ${ }^{8-12}$ and abnormalities of fibrinolysis have also been described ${ }^{13-15}$ but little attention has been focused on the role of platelets which are known to contribute to all aspects of normal haemostasis. We have therefore examined the risk of thromboembolic disease and undertaken a study of platelet function, in patients with inflammatory bowel disease attending a gastroenterology follow up clinic.

Departments of Gastroenterology, Clinical Haematology and Nuclear Medicine, Dudley Road Hospital, Budley Road Hospital M J Webberley M T Hart V Melikian

Correspondence to: Dr M J Webberley, Department of Rount B18 7QH.

Accepted for publication 6 July 1992 reactive protein, albumin, $\alpha_{1}$ acid glycoprotein, haemoglobin, and erythrocyte sedimentation rate). These were used to confirm disease activity status, but if a clear discrepancy arose then more emphasis was given to these indicators and disease activity estimated by an independent observer. A $60 \mathrm{ml}$ venous blood sample was obtained with minimal stasis after a fat free breakfast, of which $20 \mathrm{ml}$ aliquot was allowed to stand for measurement of $C$ reactive protein, $\alpha_{1}$ acid glycoprotein, and anticardiolipin antibodies. The remainder was immediately anticoagulated using freshly prepared $3.8 \%$ disodium citrate solution (at a ratio of nine parts blood to one part anticoagulant).

A separate $11.5 \mathrm{ml}$ sample of blood was also taken, of which $9 \mathrm{ml}$ was placed directly in a precooled tube containing $0.95 \mathrm{ml}$ of EDTA and a $0.04 \mathrm{M}$ solution of indomethacin (for measurement of thromboxane $B_{2}$ and 6-keto-prostaglandin $F_{1} \alpha$ ) and the remaining $2.5 \mathrm{ml}$ of blood was placed in another precooled tube containing a solution of EDTA and theophyllin (Amersham International plc, Bucks) (for measurement of $\beta$ thromboglobulin). Both tubes were rapidly cooled, centrifuged at $1200 \mathrm{rpm}$ at $4^{\circ} \mathrm{C}$, and the supernatant removed for assay.

The following studies were then undertaken: (a) Platelet count, platelet distribution width (PDW), mean platelet volume (MPV), and platelet crit (using a Technicon $\mathrm{H} 1$ blood analyser); (b) erythrocyte sedimentation rate (Westergren); (c) platelet 'adhesiveness' (Salzmann); (d) platelet aggregation $^{18}$; (e) plasma $\beta$ thromboglobulin (BTG), thromboxane $\mathrm{B}_{2}\left(\mathrm{TBxB}_{2}\right)$ and 6-ketoprostaglandin $\mathrm{F}_{1} \alpha$ (Amersham International plc); (f) platelet lifespan.

PLATELET ADHESIVENESS (29 patients)

This was assessed using Salzmann's method and was facilitated by the use of a commercially available 'Adeplat T' kit (Semmelweis, Milan, Italy).

PLATELET AGGREGATION STUDIES (104 patients) Throughout the platelet aggregation studies platelets were only exposed to plastic or siliconised surfaces. All tests were performed in duplicate and in parallel with tests on age and sex matched controls and were performed at $37^{\circ} \mathrm{C}$ using an LEA 4 channel platelet aggregometer (Bio/data Corporation). Platelet rich plasma (PRP) was generated by centrifugation of whole blood at $600 \mathrm{~g}$ for 12 minutes and the platelet count adjusted to $300 \times 10^{9} / \mathrm{l}$ using platelet poor plasma (PPP). A $0.45 \mathrm{ml}$ aliquot of PRP from each patient and control was added to each channel of the aggregometer, a stir bar added, 
the velocity of stir bar rotation reduced to 800 $\mathrm{rpm}$, and the samples examined for spontaneous platelet aggregation (SPAG). Subsequently, serial dilutions of adenosine diphosphate (ADP), collagen, ristocetin, and arachidonic acid (at starting concentrations of $10 \mu \mathrm{mol} / 1,5 \mu \mathrm{g} / \mathrm{ml}$, $1.25 \mu \mathrm{g} / \mathrm{ml}$, and $25 \mu \mathrm{mol} / \mathrm{l}$ respectively) were freshly prepared and used as aggregating agents, with $44 \cdot 7 \mu$ l of aggregating agent being added to each successive $0.45 \mathrm{ml}$ aliquot of patient and control PRP. The maximum aggregation velocity for test $v$ control was recorded as well as the endpoint dilution of aggregating agent at which platelet aggregation would still occur.

In those patients in whom spontaneous platelet aggregation was found, further studies were performed. Gel filtration ${ }^{19}$ was used to separate the platelets from plasma in PRP samples of patients who had shown SPAG (platelet viability was assessed by aggregation studies performed on platelets resuspended in autologous plasma). Patients' platelets were then resuspended in ABO compatible control plasma and tested again for spontaneous aggregation. Similarly, plasma from patients in whom SPAG was seen was added at a ratio of $1: 1$ by volume to the PRP of controls and tested for SPAG. The 104 patients were followed up over an 18 month period. Platelet aggregation studies were repeated for those patients in whom there was a change of disease activity status.

PLASMA BTG, TBXB $_{2}$, AND 6-KETO-PROSTAGLANDIN $F_{1} \alpha(62$ patients)

Plasma $\beta$ thromboglobulin, thromboxane $B_{2}$, and 6-keto-prostaglandin $F_{1} \alpha$ (the stable metabolites of thromboxane $\mathrm{A}_{2}$ and prostacyclin)

TABLE I Patient and control details

\begin{tabular}{|c|c|c|c|c|c|c|c|}
\hline Study group & No & Age & Men & Women & $\begin{array}{l}\text { Active } \\
\text { disease }\end{array}$ & $\begin{array}{l}\text { Medical RX } \\
\text { (steroids) }\end{array}$ & $\begin{array}{l}\text { Previous } \\
\text { surgery }\end{array}$ \\
\hline $\begin{array}{l}\text { Crohn's disease } \\
\text { Ulcerative colitis } \\
\text { Control }\end{array}$ & $\begin{array}{l}40 \\
64 \\
89\end{array}$ & $\begin{array}{l}49 \\
51 \\
45\end{array}$ & $\begin{array}{l}14 \\
35 \\
48\end{array}$ & $\begin{array}{l}26 \\
29 \\
41\end{array}$ & $\begin{array}{l}12 \\
10\end{array}$ & $\begin{array}{l}17(7) \\
45(11)\end{array}$ & $\begin{array}{l}18 \\
12\end{array}$ \\
\hline Site of disease & & \multicolumn{2}{|c|}{ Total } & $\begin{array}{l}\text { Diffuse } \\
\text { disease }\end{array}$ & & $\begin{array}{l}\text { Segmental } \\
\text { small bowel }\end{array}$ & Colitis \\
\hline \multirow[t]{2}{*}{ Crohn's disease } & & \multicolumn{2}{|c|}{40} & 10 & & 18 & 12 \\
\hline & & & & $\begin{array}{l}\text { Distal } \\
\text { disease }\end{array}$ & & $\begin{array}{l}\text { Left sided } \\
\text { disease }\end{array}$ & $\begin{array}{l}\text { Total } \\
\text { colitis }\end{array}$ \\
\hline Ulcerative colitis & & 6 & & 4 & & 32 & 28 \\
\hline
\end{tabular}

TABLE II Comparison of SPAG and history of thrombosis

\begin{tabular}{llllc}
\hline Patient no & Diagnosis & Site of thrombosis & Age & SPAG \\
\hline 1 & Ulcerative colitis & $\begin{array}{c}\text { Deep vein thrombosis/pulmonary embolus } \\
\text { Deep vein thrombosis/pulmonary embolus } \\
\text { fatal myocardial infarction }\end{array}$ & 50 & + \\
3 & Crohn's disease & 55 & + \\
4 & Crohn's disease & $\begin{array}{c}\text { Deep vein thrombosis/pulmonary embolus, } \\
\text { transient ischaemic attacks }\end{array}$ & 55 & + \\
5 & Ulcerative colitis & $\begin{array}{c}\text { Pulmonary emboli fatal cortical vein } \\
\text { thrombosis/pulmonary embolus }\end{array}$ & 32 & + \\
6 & Crohn's disease & $\begin{array}{c}\text { Deep vein thrombosis/pulmonary } \\
\text { embolus }\end{array}$ & 36 & - \\
7 & Ulcerative colitis & $\begin{array}{c}\text { Deep vein thrombosis/pulmonary } \\
\text { embolus }\end{array}$ & 62 & + \\
8 & Crohn's disease & $\begin{array}{c}\text { Deep vein thromboses severe } \\
\text { ischaemic heart disease }\end{array}$ & 62 & + \\
\hline
\end{tabular}

Spontaneous platelet aggregation (SPAG) in patients with a history of thromboembolic complications. ('Age' denotes age at which first thromboembolic event occurred.) were measured by radioimmunoassay (Amersham International plc).

\section{PLATELET LIFE SPAN (10 patients)}

Platelet life span was assessed in 10 patients with active IBD using indium-111 oxine labelled platelets. Platelets were separated from plasma and labelled according to methods previously described. ${ }^{20}$ Viability following the labelling procedure was assessed by aggregation studies and by comparison of hepatic and blood pool curves (where increasing hepatic sequestration without a plateau being reached implied significant platelet damage). ${ }^{21}$ Statistical significance of differences between groups was determined by Mann-Whitney U test. Correlations were sought with Spearman's rank correlation test.

\section{Results}

In the study group of 104 patients, 40 had Crohn's disease and 64 ulcerative colitis (of whom 14 had undergone previous panproctocolectomy). Table I gives details of disease distribution. Twenty two patients were assessed as having active disease at the time of study. Seven patients had extra intestinal manifestations of disease, two had established primary sclerosing cholangitis (PSC), three had probable early PSC, and two had ankylosing spondylitis. No patient in the ulcerative colitis panproctocolectomy group had evidence of extra intestinal disease.

Sixty two patients were taking 5-aminosalicylic acid products and 18 of these were also receiving steroid medication. Cardiolipin antibodies were absent in all patients apart from one 49 year old Asian man who was later found to have type IIb hyperlipidaemia. The importance of this is unexplained.

\section{THROMBOEMBOLISM (Table II)}

Eight patients were found to have a previous history of thromboembolism and in seven there were recurrent complications.

Two patients died from causes directly attributable to thromboembolic complications over the 18 month follow up period.

PLATELET MORPHOLOGY AND NUMBER (Table III) Eight of 40 patients with Crohn's disease and seven of 64 patients with ulcerative colitis had significantly raised platelet counts $\left(<420 \times 10^{9} / 1\right)$. The counts were higher in the patients with Crohn's disease than in those with ulcerative colitis but did not reach statistical significance. Platelet counts were generally higher in patients with active disease but not significantly so. The platelet distribution width was normal in all patients, but the mean platelet volume was generally lower in patients than in controls. No statistical significance was achieved.

\section{PLATELET ADHESION}

This test was discontinued after studying 29 patients and matched controls. Results obtained 
TABLE III Quantitative and morphological aspects of platelets

\begin{tabular}{lllllll}
\hline & & $\begin{array}{l}\text { Thrombocytosis } \\
(n)\end{array}$ & $\begin{array}{l}\text { Mean platelet } \\
(\times 109 / l) \\
(S D)\end{array}$ & $\begin{array}{l}\text { MPV }(f)) \\
(S D)\end{array}$ & $\begin{array}{l}\text { PDW } \\
(\%)\end{array}$ & $\begin{array}{l}\text { Platelet } \\
\text { aggregates } \\
(\text { n/field })\end{array}$ \\
\hline Crohn's disease & 40 & 8 & $329(118)$ & $7 \cdot 78(0.94)$ & 49 & 4 \\
Ulcerative colitis & 50 & 7 & $286(91)$ & $8 \cdot 13(0.93)$ & 48 & 4 \\
Panproctocolectomy & 14 & 0 & $337(78)$ & $8 \cdot 11(0.93)$ & 48 & 1 \\
Controls & 84 & 0 & $271(65)$ & $8 \cdot 20(0.94)$ & 48 & 1 \\
\hline
\end{tabular}

Platelet count, mean platelet volume (MPV), platelet distribution width (PDW), and platelet aggregates (per high power field) in controls and patients with Crohn's disease, ulcerative colitis, and patients with ulcerative colitis who have undergone panproctocolectomy.

TABLE IV Platelet aggregation studies

\begin{tabular}{llllll}
\hline & & SPAG & $\begin{array}{l}S P A G \\
(\%)(S D)\end{array}$ & $\begin{array}{l}S P A G \\
(\% / t)(S D)\end{array}$ & $\begin{array}{l}\text { Platelet } \\
\text { hypersensitivity } \\
(n)\end{array}$ \\
\hline Crohn's disease & 40 & $18^{\star}$ & $48(35)$ & $70(35)$ & $29^{\star}$ \\
Ulcerative colitis & 50 & $11^{\star}$ & $54(32)$ & $65(30)$ & $1^{\star}$ \\
Panproctocolectomy & 14 & $6^{\star}$ & $54(36)$ & $65(34)$ & $7^{\star}$ \\
Controls & 84 & 0 & 0 & 0 & 0 \\
\hline
\end{tabular}

Spontaneous platelet aggregation and platelet hypersensitive in controls, patients with Crohn's disease, ulcerative colitis, and patients with ulcerative colitis who have undergone panproctocolectomy. ${ }^{\star} \mathrm{p}<0.001$.
Figure 1: Reproducible aggregation in a patient with Crohn's disease (upper curve). The control platelets eventually aggregate when adenosine diphosphate is added (lower curve). spontaneous platelet were non-reproducible and therefore impossible to interpret. In those patients tested there was no significant abnormality of adhesion detected and no difference between patients and controls.

PLATELET AGgREgATION STUdies (Table IV)

(a) Spontaneous platelet aggregation. Reproducible SPAG was observed in 18 of 40 patients with Crohn's disease and 17 of 64 patients with ulcerative colitis (including six of 14 patients with ulcerative colitis who had undergone previous panproctocolectomy), and in nine of the 36 patients with only distal disease (Fig 1). This phenomenon was not observed in the control group and was a highly significant finding $(\mathrm{p}<0.0001$ and $\mathrm{p}<0.0001)$ for both Crohn's disease and ulcerative colitis groups. There was no difference between the Crohn's disease and ulcerative colitis groups and no correlation with disease activity, site of disease, and current treatment.

Eight of nine patients whose disease activity status changed during the course of the study retained this abnormality. Two patients who were taking non-steroidal anti-inflammatory drugs (which exert an anti-aggregatory effect) at the time of study, also showed SPAG. Seven of eight patients with previous thromboembolism showed SPAG.

(b) Aggregation studies with aggregating agents. A further 11 patients in the Crohn's disease group and nine in the ulcerative colitis group (including one in the panproctocolectomy group) had marked sensitivity of platelets to low pared with controls (this arbitrarily being defined as more than a threefold difference in endpoint dilution of aggregating agent). (Fig 2). There was a highly significant difference between patients and controls for each of the three aggregating agents, adenosine diphosphate, collagen, and arachidonic acid $(\mathrm{p}<0.001, \mathrm{p}<0.001$, and $\mathrm{p}<0.001)$. There was no difference for ristocetin, or between patients with Crohn's disease and ulcerative colitis and no correlation with disease activity.

(c) Gel filtered platelets. Gel filtration of PRP produced on average a platelet yield of approximately $60 \%$. The platelets functioned adequately in 12 of $20(60 \%)$ patients with SPAG when resuspended in autologous plasma. The platelets from six patients $(50 \%)$ showed SPAG when suspended in ABO compatible control plasma, even with PRP platelet counts of less than $100 \times 10^{\%} / 1$. Conversely, the plasma from the same patients was not seen to induce SPAG in control PRP.

\section{BTG, TBXB $_{2}$, AND 6-KOTO-PROSTAGLANDIN $\mathrm{F}_{1} \alpha$}

(Table V)

Plasma thromboxane $B_{2}$ and $\beta$-thromboglobulin were significantly higher in patients than in controls $(p<0.001, p<0.001)$. There was no difference between patients with Crohn's disease and those with ulcerative colitis and no correlation with disease activity. There was no significant difference between the patients and control, groups in the 6-keto-prostaglandin $F_{1} \alpha$ levels
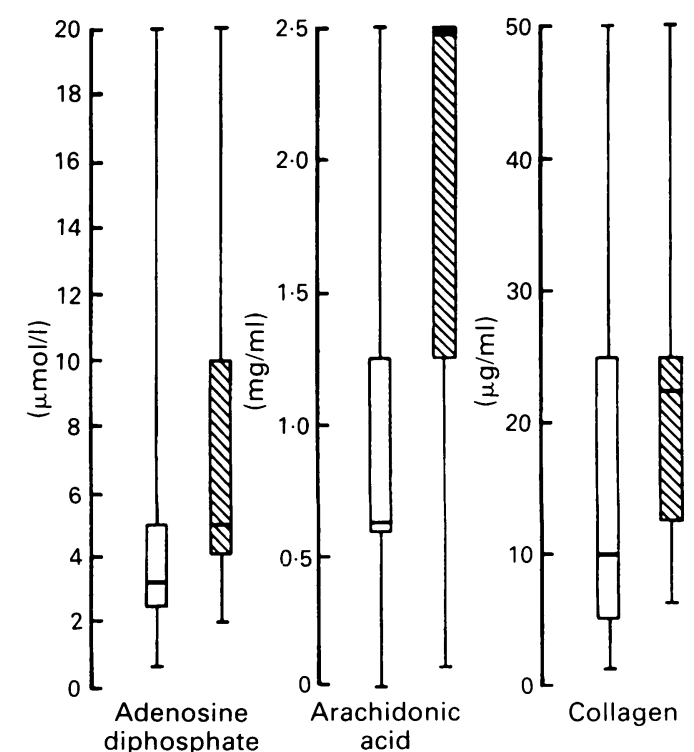
concentrations of aggregating agents when com-

Figure 2: Box and whisker plots showing distribution and median values for end point concentration of aggregating agents, at which platelets would still aggregate for patients $(\square)$ and controls $(\mathbb{N})$ 
TABLE V Platelet and endothelial cell release proteins

\begin{tabular}{|c|c|c|c|c|c|}
\hline & (n) & $\begin{array}{l}\text { Thromboxane } \\
B_{2} \\
(p g / t u b e)\end{array}$ & $\begin{array}{l}\text { 6-keto-prostaglandin } \\
F_{/}(\ell \\
(p g / t u b e)\end{array}$ & $\begin{array}{l}\text { 乃 Thromboglobulin } \\
\text { 6-keto-prostaglandin } F_{1 \alpha} \\
\text { (pg/tube) }\end{array}$ & $\begin{array}{l}\text { 乃 Thromboglobulin } \\
(n g / l)\end{array}$ \\
\hline $\begin{array}{l}\text { Patients } \\
\text { (SD) } \\
\text { Controls } \\
\text { (SD) }\end{array}$ & $\begin{array}{l}62 \\
62\end{array}$ & $\begin{array}{c}53 \cdot 11^{\star} \\
(17 \cdot 33) \\
36 \cdot 0 \\
(14 \cdot 87)\end{array}$ & $\begin{array}{c}10 \cdot 58 \\
(3 \cdot 18) \\
9 \cdot 10 \\
(3 \cdot 46)\end{array}$ & $\begin{array}{c}5 \cdot 62 \\
(2 \cdot 86) \\
6 \cdot 38 \\
(8 \cdot 47)\end{array}$ & $\begin{array}{c}84 \cdot 6 \dagger \\
(54 \cdot 0) \\
36 \cdot 0 \\
(18 \cdot 0)\end{array}$ \\
\hline
\end{tabular}

Plasma thromboxane $B_{2}$, 6-keto-prostaglandin $F_{1} \alpha, \beta$ thromboglobulin, and the ratio of thromboxane $B_{2}$ to 6-keto-prostaglandin $F_{1} \alpha$, in patients and controls.

$\star \mathrm{p}<0.001,+\mathrm{p}<0.001$

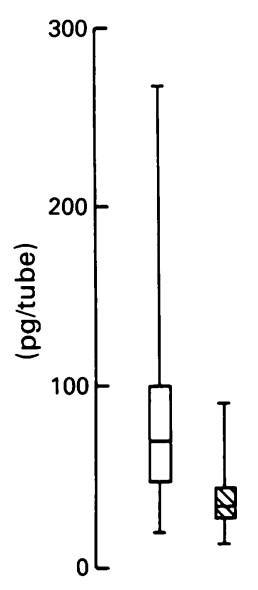

Thromboxane $B_{2}$

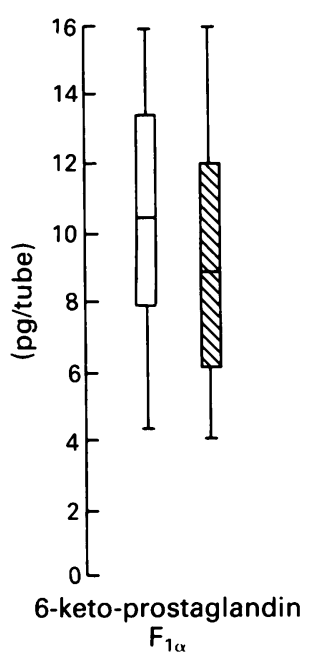

$F_{1 \alpha}$

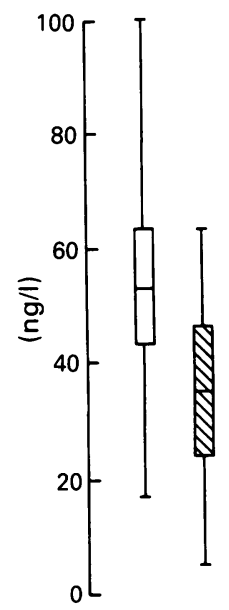

$\beta$ thromboglobulin
Figure 3: Box and whisker plots showing distribution and median values for plasma levels of thromboxane $B_{2}, 6$-keto-prostaglandin $F_{1} \alpha$ and $\beta$ thromboglobulin for patients $(\square)$ and controls $(\mathbf{N})$.

and in the $\mathrm{TBXB}_{2}: 6$-keto-prostaglandin $\mathrm{F}_{1} \alpha$ ratio (Fig 3).

\section{PLATELET LIFESPAN}

The in vitro aggregation response of patients' PRP to $10 \mu \mathrm{M} A D P$ after separation and labelling with ${ }^{11}$ In oxide compared favourably with that of controls. Hepatic sequestration after reinjection reached a plateau and matched the curve for the blood pool in all patients. These results suggest that minimal damage was incurred by the platelets as a result of the separation and labelling procedures. ${ }^{20}$ The platelet life span in all 10 patients was normal (seven to ten days), although two patients had borderline low results (Fig 4).

Figure 4: Platelet survival in patients with Crohn's disease, ulcerative colitis, ard idiopathic thrombocytopenic purpura (ITP).
Screening of the abdomen for abnormal uptake showed no evidence of sequestration of platelets in the bowel wall at sites of active disease. There was no difference in platelet survival between the Crohn's disease and ulcerative colitis groups and no correlation with platelet count or spontaneous platelet aggregation.

\section{Discussion}

The association between thromboembolism and inflammatory bowel disease was first described by Bargen and Barker in 1936. The work, based mainly on clinical observation, described severe and life threatening thromboembolism, particularly in young patients with active ulcerative colitis, and the authors concluded that a coagulopathy was to blame and that it probably related to 'platelet function or the ease in which thromboplastin in generated.' Studies of blood coagulation have shown several abnormalities ${ }^{7-12}$ with raised levels of fibrinogen, fibrinopeptide $A$, factors II, V, and VIII having been described. In all cases fluctuating levels of these factors have matched that of the underlying bowel disease implying an acute phase response.

Fibrinolysis has also been shown to be abnormal in patients with inflammatory bowel disease, ${ }^{13-15}$ with raised levels of plasminogen activator inhibitor and decreased tissue plasminogen activator having been described, although no correlation with disease activity was found in this instance. Platelets have received less attention, which is surprising considering the essential role they play in normal haemostasis and the contribution they make to normal coagulation and fibrinolysis. Although abnormalities have been described, ${ }^{22-24}$ studies have generally been small and inconclusive.

We have shown a significant risk of recurrent thromboembolism in patients with inflammatory bowel disease (8/104) and in most cases this complication occurred during disease quiescence (and in some cases preceded the diagnosis of the underlying bowel disorder). Platelet aggregation and in particular spontaneous aggregation was found to be markedly active in a high proportion of patients and spontaneous platelet aggregation was observed in seven of the eight patients with previous thromboembolism. Spontaneous platelet aggregation has been described in other disorders associated with thromboembolic disease. ${ }^{25-27}$ In addition, circulating plasma levels of the platelet release proteins $\beta$ thromboglobulin and thromboxane $B_{2}$ were also found to be raised, providing in vivo evidence for increased platelet activation. No correlation between abnormal platelet function and disease activity was observed and the features of abnormal platelet function were retained in patients who experienced a change in disease activity status during the study period. In addition, patients with ulcerative colitis who had undergone previous panproctocolectomy also showed these abnormalities. The mean platelet volume of patients especially of those with SPAG, was generally lower than that of controls. This would tend to rule out the possibility of an abnormal population of younger, more active (and larger) platelets circulating in patients with inflam- 
matory bowel disease because of high platelet turnover. ${ }^{28}$ Platelet life span was normal in all 10 patients studied (although two patients had borderline low values), which suggests that the increased platelet consumption taking place is of a low grade nature and more likely to occur at the microvascular level. These results would support the hypothesis of a small vessel vasculitic/thrombotic cause in patients with Crohn's disease, ${ }^{7}$ although in our study patients with ulcerative colitis were found to be equally at risk.

Our studies with gel filtered platelets suggest that the abnormalities observed are due to an inherent platelet defect and not due to circulating platelet activators, although potential candidates for circulating activators would have to include bacterial lipopolysaccharides (which have been shown to include surface tissue factor expression in monocytes, which is a potent activator of platelets) $)^{122}$ and bacterial toxins such as verotoxins (which have been shown to induce SPAG in children with the haemolytic uraemic syndrome).$^{30}$ It is interesting that two patients currently taking cyclooxygenase inhibiting drugs (non-steroidal anti-inflammatory drugs) also had SPAG, implying that prostaglandin synthesis is not a primary mechanism in the development of this phenomenon.

In conclusion, we have shown a high risk of thrombosis in patients with inflammatory bowel disease in addition to markedly abnormal platelet function. Both abnormalities are unrelated to the underlying bowel disease activity and imply that platelet hyperaggregation may be important in developing thrombosis in such patients. In view of our findings, we suggest that tests for spontaneous platelet aggregation should be included routinely particularly in patients who are at increased risk of thromboembolism. Prophylactic antithrombotic drugs could then be given should the test prove positive. Abnormal platelet function might also contribute to the underlying pathological process and supports the hypothesis of a microvascular thrombotic cause in the pathogenesis of IBD.

1 Bargen JA, Barker NW. Extensive arterial and venous thrombosis complicating chronic ulcerative colitis. Arch Intern Med 1936; 58: 17-31.

2 Edwards FC, Truelove SC. The course and prognosis of ulcerative colitis. Part III. Complications. Gut 1964; 5: 1-15.

3 Kehoe FL, Newcomer KL. Thromboembolic phenomena in ulcerative colitis. Two case reports. Arch Intern Med 1964; 113: 711-5.

4 Graef V, Baggenstoss AH, Sauer WG, Spittell JB. Venous thrombosis occurring in non-specific ulcerative colitis. A thrombosis occurring in non-specific ulcerative colitis
necropsy study. Arch Intern Med 1966; 117: 377-82.

5 Silverstein A, Present DH. Cerebrovascular occlusion in relatively young patients with regional enteritis. $\mathcal{F} A M A$ 1971; 215: 976
6 Barker NW. Current status of the problems of thrombosis. Circulation 1958; 17: 487-96

7 Wakefield AJ, Sawyerr AM, Dhillon AP, Pittilo RM, Rowles PM, Lewis AAM, et al. Pathogenesis of Crohn's disease: multifocal gastrointestinal infarction. Lancet 1989; ii: 1057 62

8 Farmer RG, Scudmore HH, Bayrd ED. Comparison of clinical findings and haematologic changes in patients with chronic ulcerative colitis. Am f Gastroenterol 1963; 40: 601-11.

9 Spittell JA, Owen CA, Thompson JH, Sauer WG. Hypercoaguability and thrombosis in chronic ulcerative colitis. Coll Paper Mayo Clinic 1964; 55: 53-7.

10 Lee CL, Spittell JA, Sauer WG, Owen CA, Thompson JH. Hypercoaguability associated with chronic ulcerative colitis: changes in blood coagulation factors. Gastroenterolog $v 1968$; 54: 76-85.

11 Lam A, Borda IT, Inwood MJ, Thomson S. Coagulation studies in ulcerative colitis and Crohn's disease. Gastroenterology 1975; 68: 245-51.

12 Edwards RL, Levine JB, Green R, Duffy M, Mathews E, Brande W. Activation of blood coagulation in Crohn's disease. Increased plasma fibrinopeptide A levels and enhanced generation of monocyte tissue factor activity. enhanced generation of monocy

13 Kwaan HC, Cocco A, Mendeloff AI, Astrupp T. Fibrinolytic activity in the normal and inflamed rectal mucosa. Scand $\mathcal{F}$ Gastroenteral $1969 ; 4: 441-5$.

14 Kondo M, Hotta T, Takemura T, Yoshikawa T, Fukomot K. Treatment of ulcerative colitis by direct administration of an antifibrinolytic agent as an enema. Hepatogastroenterolog $y$ 1981; 28: 270-3

15 Jong EDE, Porte RJ, Knot EAR, Verheijen JH, Dees J. Distributed fibrinolysis in patients with inflammatory bowel disease. A study in blood plasma, colon mucosa and faeces. Gut 1989; 30: 188-94.

16 Best WR, Becktel JM, Singleton JW, Kern F. Development of Crohn's disease activity index. Gastroenterology 1976; 70: 439-44.

17 Truelove SC. Witts LJ. Cortisone in ulcerative colitis. BMJ 1955; ii: $1041-8$.

18 Born WR. Aggregation of blood platelets by adenosine diphosphate and its reversal. Nature 1962; 194: 927

19 Tangen O, Berman HJ, Marfey P. Gel-filtration: a new technique for separation of blood platelets from plasma. Thromb Diath Haemorrh 1971; 25: 268-78.

20 Hawker RJ, Hawker LM, Wilkinson AR. Indium (''In)labelled human platelets: optimal method. Clin Sci 1980; 58: 243-8

21 Peter AM, Saverymuttu SH, Malik F, Ind PW, Lavender JP. Intrahepatic kinetics of "'Indium-labelled platelets. Thromb Haemost 1985; 54:595-8.

22 Mori K, Hikami W, Hiwatashi N, Sugaik K, Goto Y. Studies on blood coagulation in ulcerative colitis and Crohn's disease. Tohoku $\mathcal{F}$ Exp Med 1980; 132: 93-101.

23 Knot E, Ten Cate JW, Leeksma OCH, Tytgat GN, Vreeken J. No evidence for a prothrombotic state in stable chronic inflammatory bowel disease. I Clin Pathol 1983; 36: 1387-90.

24 Simi M, Leardi S, Tebano MT, Castelli M, Costantini FM, Spevanza V. Raised plasma concentrations of platelet factor 4 (PF4) in Crohn's disease. Gut 1987; 28: 336-8

25 Mustard JF, Packham MA. Platelets and diabetes mellitus. NEngl F Med 1977; 297: 1345-7.

26 Ten Cate JW, Vos J, Oosterhuis H, et al. Spontaneous platelet aggregation in cerebrovascular disease. Thromb Haemost 1978; 39: 223 .

27 Zahavi J. The role of platelets in myocardial infarction, ischaemic disease, cerebrovascular disease, thromboembolic disorders and acute idiopathic pericarditis. Thromb Haemost 1977; 38: 1073

28 Thompson CB, Jakubowski JA, Quinn PG, Deykin D., Valeri CR. Platelet size and age determine platelet function independently. Blood 1984; 63: 1372-5.

29 Schwartz BS, Monroe MC. Human platelet aggregation is inititiated by peripheral blood mononuclear cells exposed to bacterial iipoplysaccharide in vitro. $\mathcal{F}$ Clin Invest 1986; 78: 1136-41.

30 Rose PE, Armour JAB, Williams CE, Hill FG. Verotoxin and neuraminidase induced platelet aggregation activity in plasma: their possible role in the pathogenesis of the
haemolytic uraemic syndrome. Br f Haematol 1985; 38: haemolytic 